\title{
Evaluation of Information and Public Awareness Programme of MNRE in India
}

\author{
Pradeep Kumar Panda \\ Indian Institute of Public Administration, New Delhi \\ *Correspondence: pradeep25687@yahoo.co.in
}

\begin{abstract}
The Information \& Public Awareness (I\&PA) Programme of the Ministry of New and Renewable Energy (MNRE) has been existing since the inception of the Ministry in 1992. The programme is being implemented as a central sector scheme with full funding from the central budget. The Ministry uses variety of media like electronic, print and outdoor publicity through exhibitions, bus panels, hoardings, kiosks, paintings and other outdoor media activities for popularization of new and renewable energy systems and devices throughout the country. The Ministry participates in different Districts, States and National level exhibitions mainly through State Nodal Agencies (SNAs). With the analytical frame of reference, the study has taken into account mixed approaches to suitably take the feedback of stakeholders. In the study, the purpose was to analyze the progress of programme at all India level. Accordingly, data and information were collected through survey method and participatory discussion with target groups i.e. rural women, farmers (solar pumps), rooftop solar users, other sources of renewables, etc. There were several meetings with renewable energy beneficiaries/potential users and agencies created at State/district level to implement ministry's scheme. Both quantitative and qualitative information have been garnered. The evaluation study attempts to assess the impact of I\&PA and to identify specific bottlenecks in implementation and optimum levels of support needed for effective implementation. It is found that the implementation of I\&PA Programme is meeting the desired objectives. Awareness about the scheme is found among the state governments and public in the field. Thus, the scheme has largely been effective in the promotion of renewable energy, in its overarching objectives.
\end{abstract}

Keywords:Renewable Energy, MNRE, Information, Public Awareness, Evaluation, India

\section{Introduction}

As countries around the world battle with the unavoidable destroying effect of environmental change, which to a great extent has been brought about by human-centric activities, the role of renewable energy becomes essential to restore the balance. In an effort to move towards this direction, many developed and developing countries have begun giving supremacy to this source of energy to quickly build the level of environmentally friendly power in the general energy blend of their economies. India too is very ambitious in its targets for promoting renewable energy. To meet its ambitious targets and commitment to the entire world in the fight against climate change, India has been rolling out multiple initiatives, programmes, policies and incentives to accelerate the development of the renewable energy sector.

Ministry of New and Renewable Energy (MNRE) came into existence in the year 1992 and is the nodal Ministry of the Government of India at the national level for all matters relating to new and renewable energy such as solar, wind, biomass, small, hydro, hydrogen, bio fuels, geothermal etc. The Ministry aims to promote renewable energy technologies and increase the contribution of renewable energy in the total energy mix today and in the years to come. In order to percolate the benefits and usage of renewable to the masses, information dissemination and publicity have to play a crucial role. Further, in the fast changing technological and policy landscape of renewables, the role of information and public awareness has become vital for creating mass awareness.

I\&PA Programme of the Ministry of New and Renewable Energy (MNRE) has been existing since the inception of the Ministry in 1992 and during the last year of $12^{\text {th }}$ plan i.e. 201617, the program was reviewed by an Expert Committee comprising members both from the MNRE and other expert bodies such as All India Radio, NFDC, BOC, Doordarshan, Jamia Millia University. Accordingly the scheme guidelines were prepared and approved by Hon'ble Minister at a total outlay of Rs. 66 crore for a period of three years i.e. 2017-18 to 2019-20. Further, the I\&PA program was extended for a period of one year i.e. 2020-21 in line with the instructions of Department of Expenditure, GoI. The programme is being implemented as central sector scheme with full funding from the central budget. The main objectives of the I\&PA Programme are to create awareness, popularise and disseminate Government of India's (GoI) plans and programmes in new and renewable energy such as solar energy, wind energy, bioenergy, small hydro power, waste to 
power, etc., and their benefits; facilities, incentives available, technological developments and promotional activities. Further it aims to make people aware about the availability of renewable including their proper use, repair and maintenance facilities, etc., expand and promote the market for renewable energy systems \& devices, raise awareness about renewable amongst students, teachers, scientists and public at large. The Programme is implemented through pragmatic use of existing Government channels viz. State Nodal Agencies (SNAs), Bureau of Outreach \& Communications (BOC) (earlier known as DAVP), National Films Development Corporation (NFDC), Doordarshan, All India Radio (AIR), etc., among others.

The Ministry uses variety of media like electronic, print and outdoor publicity through exhibitions, bus panels, hoardings, kiosks, paintings and other outdoor media activities for popularization of new and renewable energy systems and devices throughout the country. The Ministry participates in different District, State and National level exhibitions mainly through State Nodal Agencies (SNAs). On some occasions, Ministry also participates directly in exhibitions organized by important organizations/bodies like, Indian Trade Promotion Organization (ITPO), Confederation of Indian Industries (CII), Federation of India Chambers of Commerce \& Industry (FICCI), etc. In addition, under the I\&PA programme, various educational excursion/tours of students of different schools/ institutions and media persons (both print and electronic) to different renewable energy project sites are organized to stimulate awareness amongst students, youth and media persons.

Background of the Scheme: In terms of renewable energy capacity, India stands among the top five countries in the world. The Ministry has implemented various policies and programmes for achieving the goals in renewable energy sector. Waiver of Inter-state transmission charges for sale of solar and wind power; Renewable Purchase Obligation trajectory, competitive bidding guidelines for procurement of solar and wind power; flexibility in generation and scheduling of thermal power stations; solar cookers programme; solar-wind hybrid policy; solar PV manufacturing linked with assured take-off; Atal Jyoti Yojana and standards for deployment of Solar PV systems are some of the major initiatives. In order to percolate all these initiatives, benefits and usage of renewable to the masses, information dissemination and publicity is essential. In this background, I\&PA programmes for renewable energy were conceptualized and developed for implementation since the inception of the MNRE in 1992. The broad objective of the $I \& P A$ programme is to create awareness and disseminate GoI's plans and programmes in new and renewable energy area. Various means are deployed for publicising renewable energy throughout the country including through electronic media, print media, outdoor media and exhibitions, tour visits and workshops/ training for medial students, renewable energy tableau for republic day parade, other media as per requirement. The campaigns are being implemented using different tools of advertisement and publicity, viz. TV, radio, outdoor, print and new media, digital cinema, etc. Renewable Energy has become one of the most important factors and hope for the world to preserve the pristine environment and the planet's resources for future generations. In India too, the role of renewable energy has been assuming increasing significance in recent times with the growing concern for the country's energy security and environmental sustainability of energy use. In this respect, the MNRE has taken various policy initiatives to promote renewable energy technologies and increase the contribution of renewable energy in the total energy mix today and in the years to come. The Ministry is implementing the I\&PA programme using various modes of publicity media to create awareness, popularize and disseminate GoI's plans and programmes in new and renewable energy.

\section{Objectives of the Information and Public Awareness (I\&PA) Programme}

The main objectives of the I\&PA programme are to:

a) popularize and create awareness about new and renewable energy systems and devices highlighting their benefits;

b) create mass awareness about technological developments and promotional activities taking places in renewables from time to time in the country with special focus on rural areas;

c) make people aware about the availability of renewable including their proper use, repair and maintenance facilities, etc.;

d) expand and promote the market for renewable energy systems and devices, and;

e) raise awareness about renewables amongst students, teachers, scientists and public at large.

Implementation Mechanism: The Programme is implemented using Government channels, viz.

(i) Bureau of Outreach and Communications (BOC) [earlier known as DAVP];

(ii) National Films Development Corporation (NFDC);

(iii) Doordarshan;

(iv) All India Radio (AIR);

(v) Songs and Drama Division;

(vi) State Nodal Department/ Agencies for renewable energy; and

(vii) NGOs/ Academic institution/s, etc., and participation in exhibitions of national importance by the Ministry and also through other relevant Institutions/Organization. 
It is also providing information and awareness extensively through its three autonomous Institutions i.e. NISE, NIWE and SSS-NIBE and two PSUs i.e. IREDA and SECI.

\section{Budgetary allocation and expenditure pattern}

Table 1: Budgetary Allocation and Expenditure of I\&PA (Rs. Cr)

\begin{tabular}{lrrr}
\hline \multicolumn{1}{c}{ Year } & \multicolumn{1}{c}{ BE } & \multicolumn{1}{c}{ RE } & Actuals \\
\hline $2017-18$ & 20 & 15 & 13.56 \\
$2018-19$ & 15 & 10 & 6.51 \\
$2019-20$ & 10 & 7.21 & 6.71 \\
$2020-21$ (as on & 10 & 4.7 & 1.26 \\
$17.2 .21)$ & & & \\
Total (2017-21) & 55 & 36.91 & 28.04 \\
\hline
\end{tabular}

Source: MNRE

Since the administrative approval for continuation of the programme in 2017-18, the revised expenditure and actual expenditure has been declining constantly in want of modern promotional and awareness infrastructure as stated by the Ministry's officers. The I\&PA Programme is an awareness generation scheme, wherein 99.4 per cent of the spending was done through print media and outdoor media in 2019-20 but it came down to 84.88 per cent in the financial year 2020-21 (as on $17^{\text {th }}$ February 2021). Also, in the year 2020-21, there is a substantial fall in the actual expenditure. This is mainly due to the restrictions imposed because of the Covid-19 pandemic. As a result, the major awareness generation programmes through outdoor media like exhibitions, seminars, symposiums could not be done. Therefore, the pandemic imposed restrictions on the spending pattern. The employment of archaic methods was considered the major stumbling blocks in utilizing funds to its full capacity. Due to this reason, the demands of state nodal agencies (SNAs) were also not fully considered during the period. The major activities undertaken under this item are print media, outdoor media, exhibition, seminar and symposia. The other activities were electronic media and publicity through social media.

\section{Objectives of the Study}

The objectives of the evaluation study attempts:

(i).To assess the impact of Information and Public Awareness Programme (I\&PA) objectives including activities undertaken in furtherance of each objective;

(ii).To identify specific bottlenecks in implementation and optimum levels of support needed and also identify barriers, constraints, if any with reference to all schemes/programmes of the Ministry;

(iii).To assess significant outcomes of the programme;

(iv).To identify awareness levels of potential/existing beneficiaries of MNRE schemes;

\section{Data and Methodology}

The study adopts a positivist approach. With the analytical frame of reference, the study has taken into account mixed approaches to suitably take the feedback of stakeholders. In the study, the purpose was to analyze the progress of the I\&PA Programme at all India level. Accordingly, data and information were collected through a survey method and participatory discussion with immediate stakeholders. For this purpose, question banks for various target groups were prepared. Both quantitative and qualitative information have been garnered. The evaluation study has relied upon both primary and secondary sources of data. The research instruments for data collection involved, structured interview schedule for officials, a structured questionnaire for the beneficiary, and a structured interview schedule for the scheme implementing agencies officials. Moreover, given the hardship due to pandemic situation and spread of corona virus, telephonic interviews were also conducted to elicit the required information for better results. The multiple indicators pertaining to the programme evaluation have been taken into account as to gauge the obvious impact of the scheme on the beneficiaries. The sample size of target group has been drawn in such a way that it represented the population. Stratified random sampling is used for sample selection. At first level, states are selected from each zone (North, North East, Central, East, West and South). At second level, districts are selected on the basis of presence of Solar, Wind, Hydro, Bio-energy, Hydel, Biomass and Waste to energy etc. At third level, blocks are selected. At fourth level, beneficiaries are selected using random sampling method. Following table is showing the state wise sample size of beneficiaries.

\begin{tabular}{|c|c|c|}
\hline $\begin{array}{l}\text { Sl. } \\
\text { No. }\end{array}$ & $\begin{array}{l}\text { Selected } \\
\text { States/UTs }\end{array}$ & $\begin{array}{l}\text { Sample } \\
\text { Size }\end{array}$ \\
\hline 1. & $\begin{array}{l}\text { Andhra } \\
\text { Pradesh }\end{array}$ & 95 \\
\hline 2. & $\begin{array}{l}\text { Arunachal } \\
\text { Pradesh }\end{array}$ & 14 \\
\hline 3. & Assam & 64 \\
\hline 4. & Bihar & 11 \\
\hline 5. & Chhattisgarh & 23 \\
\hline 6. & Haryana & 77 \\
\hline 7. & Ladakh & 124 \\
\hline 8. & $\begin{array}{l}\text { Madhya } \\
\text { Pradesh }\end{array}$ & 12 \\
\hline 9. & Maharashtra & 48 \\
\hline 10. & Meghalaya & 33 \\
\hline 11. & Odisha & 112 \\
\hline 12. & Punjab & 38 \\
\hline 13. & Rajasthan & 16 \\
\hline 14. & $\begin{array}{l}\text { Uttar } \\
\text { Pradesh }\end{array}$ & 372 \\
\hline
\end{tabular}




\begin{tabular}{llr}
\hline 15. & Uttarakhand & 55 \\
16. & West Bengal & 70 \\
Total & & 1164 \\
\hline
\end{tabular}

\section{Performance of the scheme based on the output/outcome indicators}

Being non-tangible and soft activities, the outcome and deliverables would be stated as the increased and equitable development and deployment of renewable, where all sections of the society are equipped with information to benefit from the provisions of GoI's programmes and schemes for renewable. In this context, details of the campaign implemented during the last five years are as follows:

\section{Electronic media}

i.Broadcasting of sponsored radio programme "Akshay urja aur hum" of 15 minutes duration in Hindi and 19 regional languages (Assamese, Bengali, Gujarati, Konkani, Kannada, Kashmiri, Khasi, Malayalam, Manipuri, Tamil, Marathi, Mizo, Nagamese, Nepali, Oriya, Punjabi, Telugu, Urdu and Garo) from 37 Vivid Bharati Stations, 20 FM Rainbow Stations, four FM Gold Stations and 33 Primary Channels/Local Radio Stations of All India Radio have been done through National Films Development Corporation.

ii.Publicity campaign with video spot of 30 second duration through "Digital Cinema" in 1500 cinema halls through NFDC in all the 28 States and eight UTs have been done.

iii.Publicity campaign with video spots of 30 seconds duration each on renewable energy systems and devices has been done through national and regional Kendras of Doordarshan.

iv.Organized short video film competition for young population in India;

v.The Ministry organized 'Global Student Solar Ambassador Workshop' in association with IIT, Bombay on 2nd October 2019 at Indira Gandhi Stadium Complex, New Delhi.

vi.The Ministry has also produced two e-booklet in flip book format on the scheme of the Ministry i.e. PM-KUSUM and reform booklet to provide all the major strides in the development and deployment of renewable energy;

vii.A short film has been produced on PM-KUSUM and RTS scheme;

viii.Two short films and radio jingles for $2^{\text {nd }}$ RE-INVEST and a short film for publicity of $3^{\text {rd }}$ RE-INVEST have been produced.

\section{Print media}

i.Ministry is publishing bi-monthly newsletter "Akshay urja" in English and Hindi separately, with a focus on national/international renewable energy developments, technological upgradation, manufacturers' detail, renewable energy education, etc. Copies of each issue of the newsletter are distributed amongst various stakeholders, universities,

IITs, schools, individuals etc. besides uploading on the Ministry's website;

ii.Publishing Ministry's annual reports regularly;

iii.Printed booklet titled "We Care for the Planet" both in English and Hindi separately during 2018;

iv.Ministry is printing booklets, folders, working paper (by International Solar Alliance) etc. from time to time on renewable energy for creating awareness and publicity;

v.Published a full page display advertisement for publicity of $2^{\text {nd }}$ RE-INVEST and also published a full page display advertisement on cost sharing basis for champions of Earth award to Hon'ble Prime Minister;

i.Ministry releasing display advertisements in English, Hindi and regional languages newspapers through BOC from time to time to create awareness highlighting the activities and achievements of the Ministry.

\section{Outdoor media}

i.Ministry, is participating in various National \& International Exhibitions from time to time in association with its Institutions and PSUs; provided financial support to State Nodal Agencies (SNAs) for various district/State-level exhibitions in different States/Union Territories of the country;

ii.Under the "Information \& Public Awareness Programme", supporting/implementing agencies were provided central financial assistance (CFA) for taking up various publicity activities like advertisements, orientation camps and outdoor publicity through hoardings, bus back panels, kiosks, wall paintings and bus stop shelters in their regional languages;

iii.Produced hoarding, posters, etc. on Ministry's schemes, viz. PM-KUSUM and RTS;

iv.Publicity of $2^{\text {nd }}$ and $3^{\text {rd }}$ RE-INVEST and media management;

v.Global student solar assembly held on 2nd October 2019, at Indira Gandhi Stadium, New Delhi;

vi.Supported seminars in the field of renewable energy;

Supported various events by extending financial and nonfinancial logo support to supporting/implementing agencies.

Table 3: Component-wise Expenditure Pattern

\begin{tabular}{ccrrr}
\hline & & \multicolumn{3}{c}{ (Rs. Lakh) } \\
Year & $\begin{array}{c}\text { Electronic } \\
\text { Media }\end{array}$ & $\begin{array}{c}\text { Print } \\
\text { Media }\end{array}$ & $\begin{array}{c}\text { Outdoor } \\
\text { Media }\end{array}$ & \multicolumn{1}{c}{ Total } \\
\hline 2017- & 907.46 & 384.01 & 65.27 & 1356.76 \\
$\mathbf{1 8}$ & $(66.88)$ & $(28.3)$ & $(4.81)$ & $(100)$ \\
$\mathbf{2 0 1 8}-$ & 40 & 603.5 & 8.21 & 651.72 \\
19 & $(6.14)$ & $(92.6)$ & $(1.26)$ & $(100)$ \\
$\mathbf{2 0 1 9}-$ & 4.01 & 664.56 & 2.69 & 671.27 \\
$\mathbf{2 0}$ & $(0.6)$ & $(99)$ & $(0.4)$ & $(100)$ \\
$\mathbf{2 0 2 0}-$ & 19.5 & 105.5 & 4 & 129 \\
$\mathbf{2 1} *$ & $(15.12)$ & $(81.78)$ & $(3.1)$ & $(100)$ \\
Total & 970.97 & 1757.57 & 80.17 & 2808.75 \\
\hline
\end{tabular}




(34.57) (62.57) (2.85) (100)
*The figures are upto February, 2021
Figures in parenthesis are percentage of total
Source: Author

The Table 3 shows the expenditure incurred under each component of the programme over the period from 2017-18 to 2020-21. It is observed that the total outlay for the I\&PA programme has reduced to almost half in 2018-19 from the preceding year level. Out of the total allocation, most of the expenditure has been incurred on print media, the share of which had an upward trend till 2019-20 but it declined steeply in the year 2020-21. Overall, in the last four years the highest spending is done through print media $(65.57 \%)$ followed by expenditure on electronic media $(34.57 \%)$ and outdoor media $(2.85 \%)$. Of the total amount spend on electronic and outdoor media, the maximum has been spent in the year 2017-18 and in 2019-20 for print media.

Coverage of beneficiaries: For the purpose of the study, the beneficiaries are classified into various categorizes like gender, physical ability, social category and rural-urban analysis. As per the Table, gender distribution of the sample, wherein 70.79 per cent are male beneficiaries and 29.21 per cent are female beneficiaries. From the surveyed states, Haryana has maximum number of female beneficiaries, i.e., 59.74 per cent whereas Uttarakhand has maximum number of male beneficiaries, i.e., 89.09 per cent. States like Assam (82.81\%), Punjab (81.58\%), Rajasthan (81.25\%) and Uttarakhand (89.09) have over 80 per cent of male beneficiaries. Whereas the states like Andhra Pradesh (55.79) and Haryana (40.26) have more than 50 per cent beneficiaries.

Benefits of the scheme: This programme has benefitted individual, institutions and communities at grassroots level across India. This Programme provided information regarding different renewable energy equipments as well as about various government subsidy schemes. Scheme like PMKUSUM, Rooftop Solar Scheme etc. were availed by many beneficiaries after knowing details of application procedure through this programme. Although the aim of the programme is to spread awareness with regard to usage of renewable energy across India irrespective of gender, caste, region etc. but the study has found that the programme is inclusive in nature as it caters to 81.01 per cent of rural population, 29.21 per cent of female beneficiaries, 6.44 per cent of divyang jans, 31.7 per cent of OBC, 13.4 per cent by SC and 23.71 per cent by ST.

\section{Issues and Challenges}

The study has found that the I\&PA programme has helped the Ministry in spreading awareness about the renewable energy among the people. But in the changing scenario there are many issues and challenges which need to be considered in order to keep it at par with the global standards because the programme at its current framework is using archaic methods at the information age where news spreads like a wildfire. The following are some of the issues and challenges with the programme in the current framework:-

Presence in digital space: MNRE has its presence only on Twitter, whereas, tableau, seminars, conferences, exhibitions, journals, etc. are still used as means of publicity for the programme. But, these are outdated as most of the population, especially youth, do not use them. Instead, popular platforms such as social media and internet need to be used in the promotion. The Ministry needs to project itself on the new social media platforms including Facebook, Instagram, LinkedIn, YouTube etc. Having a presence in social media is considered a good strategy of marketing and communication. It gives enterprises a voice and a means to converse with their existing and prospective customers. Social media is starting to become a great tool for businesses to develop and maintain strong relationships with customers.

Monitoring and evaluation: Lack of formal monitoring and evaluation activities inhibits the collection and dissemination of lessons learned from pilot projects and also prevents such lessons learned to become an input into educational policy. Wherever such activities have been conducted, the focus has been largely on program delivery and is often specific to the project itself. The MNRE needs to adopt developmental evaluation process which seeks to provide real-time feedback to support the development of innovative social initiatives. The process ensures a long-term partnership between an evaluator and a programme, where the role of the evaluator is to "elucidate team discussions with evaluative questions, data and logic, and to facilitate data-based assessments and decision-making in the unfolding and developmental processes of innovation”. The I\&PA Division of the Ministry is required to visit and monitor various exhibitions/conferences/seminars etc. for which the support has been extended from the Ministry.

Demonstration at grass-root level: Demonstration is the key mode for disseminating information and public awareness and the MNRE can use this medium to convert the potential consumers into actual ones. People are more influenced after experiencing an ideal example of new and renewable energy source and when they get to know the benefits and the outcome of these new and renewable energy sources in their vicinity. It impacts and converts the potential buyer into actual consumer. It has been felt that people are not that much inclined towards new and renewable energy sources after having a theoretical or pictorial knowledge only. But, MNRE is not pursuing any such demonstration model at the grassroot level. 
Content in regional languages: The diverse nature of India requires functionaries that can understand and cope with the diverse linguistic culture of the region. This would facilitate the people in general and youth of remote regions in particular to feel free and comfortable while availing the services under this scheme. MNRE has the content of its advertisement and publicity only in Hindi and English languages. These contents need to be developed in other local languages as well. It is learned that local language content advertising supported by technology platforms brings a win-win situation for businesses. This essentially means a situation when majority of technology platforms realize and accept the growing popularity of regional languages except Hindi and embrace these languages to target users in their language through relevant mobile ads. This will help create an environment that ensures that brand communication is done most effectively.

Funding support to State Nodal Agencies: Personalization of the content for advertisement and publicity is an expensive process and for this State Nodal Agencies, which understand the requirements of the local areas, need funds to create a personalized content, which can connect the local-ites with the components of MNRE and propel the audience to move towards the new and renewable energy. But MNRE has not allocated any funds to State Nodal Agencies during the last three years.

Branding strategy: Managing a brand and being able to promote and market it successfully is clearly vital to the prosperity of the business. The MNRE does not have any distinct branding like the Ministry of Tourism has "Incredible India". Branding helps consumers to identify and recognise the product. It is a mean of differentiating the product from the competitor's market. It is a basis of advertising and other techniques of mass selling and it helps to minimise selling costs by reducing dependence on middlemen. It tends to widen the market as need for inspection and sample is eliminated.

Capacity building: No capacity building and skill upgradation programs were conducted under the scheme for administrators which have hindered the information dissemination to the target groups. At many instances, it has been observed that the people lack awareness of the programmes run by MNRE, and those who are aware did not shift their usage to new and renewable energy due to lack of modern communication equipments.

7. Suggestion

Short term goals: Information \& Public Awareness (I\&PA) Programme of MNRE is one of its kinds which not only serves its objectives but also forms the backdrop of many other schemes through dissemination of awareness, information and communication. The MNRE needs to showcase themselves on the new social media platforms like YouTube, Facebook, Instagram, LinkedIn, Quora, Koo, Readit, Twitter, Whatsapp, QQ, Tumblr, Qzone, Baidu, Viber, Snapchat, Pinterest, Line, Telegram, Medium, etc. Having a presence in social media is considered a good strategy of marketing and communication. It gives enterprises a voice and a means to converse with their existing and prospective customers. Social media is starting to become a great tool for businesses to develop and maintain strong relationships with customers. The other important short term requirement is to enhance its outreach. The remote regions of India remain aloof of the important directions and information from government. These regions need to be covered under the scheme with utmost priority to meet the objective of the programme while harnessing the potential of all possible mediums like TV, radio, newspaper, magazines, street-plays, internet and social-media platforms in regional languages. It is inferred from the analysis of the preferences of mediums that people have more affinity towards the new and emerging platforms like internet, website and mobile apps and the government thus need to concentrate efforts in the same direction.

Mid-term goals: For the effective implementation of the Information \& Public Awareness (I\&PA) Programme of MNRE, it is a prerequisite to have suitable and sufficient infrastructure in the region. The observations during the study shows, the lack of proper telecom facility, internet facility, access to newspaper and magazines and television at many places in India. These gaps need to be fixed over time for achieving the goals of the scheme. It will also facilitate in increasing the bandwidth of the scheme. Demonstration is the key mode for disseminating information and public awareness and the MNRE can use this medium to convert the potential consumers into actual ones. People are more influenced after experiencing an ideal example of new and renewable energy source and when they get to know the benefits and the outcome of these new and renewable energy sources in their vicinity. It impacts and converts the potential buyer into actual consumer. It has been felt that people are not that much inclined towards new and renewable energy sources after having a theoretical or pictorial knowledge only. But, MNRE is not pursuing any such demonstration model at the grassroot level. The mid-term goal should also aim to bring in people of different socio-economic status under its ambit. Inclusiveness should be prioritized by the State Nodal Agencies to expand the usage of the new and renewable energy in the respective region.

Long term goals: The Information \& Public Awareness (I\&PA) Programme of MNRE needs to be fruitfully implemented for the development of the region and reducing dependence of the people over non-renewable sources of 
energy. Therefore, it requires new vigour and energy. The MNRE needs to adopt developmental evaluation process which seeks to provide real-time feedback to support the development of innovative social initiatives. The process ensures a long-term partnership between an evaluator and a programme, where the role of the evaluator is to "elucidate team discussions with evaluative questions, data and logic, and to facilitate data-based assessments and decision-making in the unfolding and developmental processes of innovation". The MNRE should focus on capacity building and skill upgradation programmes for administrators, lack of which have hindered the information dissemination to the target groups. The MNRE should have a distinct branding like Ministry of Tourism have "Incredible India". Branding helps consumers to identify and recognise the product. It is a mean of differentiating the product from the competitor's market. It is a basis of advertising and other techniques of mass selling and it helps to minimise selling costs by reducing dependence on middlemen. It tends to widen the market as need for inspection and sample is eliminated.

References

[1]. Government of India (2020), Information and Public Awareness Scheme Guideline, Ministry of New and Renewable Energy.

[2]. Government of India (2020), Union Budget 202021, Minsitry of Finance 